\title{
Cartas, Constituições e Regras do Instituto Religioso das Irmãs Mestras de Santa Dorotéia: Fontes de Pesquisa Histórica para o Estudo das Intuições Pedagógicas de Paula Frassinetti e da Constituição do Projeto Educativo dos Colégios Doroteanos ${ }^{1}$
}

Letters, Constitutions and Rules of the Master Sisters of the Saint Dorothy Religious Institute: Sources of historical research for the study of Paula Frassinetti's pedagogical intuitions and of the constitution of the education project of the Dorothean Schools

\section{Luciana de Oliveira SENE ${ }^{\bullet}$ Alessandra David Moreira da COSTA $\bullet$}

Resumo: Este trabalho propõe compreender o projeto educativo de Paula Frassinetti (Santa Paula, fundadora da Congregação de Santa Dorotéia) tecido a partir de suas intuições pedagógicas, no contexto histórico-cultural do catolicismo ultramontano. Na metodologia, utilizamos as pesquisas histórica e documental das fontes (Cartas e Constituições) deixadas por ela. A primeira escola da congregação nasceu em Quinto (1834), na Itália, e, posteriormente, houve expansão para Portugal e Brasil. O referencial teórico está centrado na análise das concepções da Igreja no século XIX, voltado à educação feminina. Sob essa ótica, as Dorotéias encarregaram-se da missão de educar as jovens dentro da moral católica, optando pelo regime de internato. Paula Frassinetti, por meio de suas intuições pedagógicas, construiu as diretrizes de sua Congregação. O resultado deste trabalho consiste em apresentar como suas intuições constituíram o projeto educativo dos Colégios Doroteanos, permeando as convenções sociais e culturais da época e local em que eram inseridas. Palavras-chave: Paula Frassinetti; Projeto Educativo; Intuições Pedagógicas; Colégios Doroteanos.

\begin{abstract}
This work proposes to arrive at an understanding of the education project of Paula Frassinetti (Saint Paula, foundress of the Saint Dorothy Congregation) which was elaborated from her pedagogical intuitions in the historical-cultural context of ultramontane Catholicism. In the methodology the historical and documental research of the sources (Letters and Constitutions) left by Paula Frassinetti were used. The first school of the Congregation was founded in Quinto (1834), in Italy, and later it expanded to Portugal and Brazil. Its theoretical reference is centered on the analysis of the conceptions of the Church in the $19^{\text {th }}$ century focussing on women's education. With this in view, the Dorotheans undertook the mission of educating youths following Catholic morality and choosing the boarding school system. Paula Frassinetti from her pedagogical intuitions had developed the guidelines of her Congregation. The result of the work at hand consists of presenting how her intuitions had constituted the education project of the Dorothean Schools, which permeated the social and cultural practices of the time and place in which they were applied.
\end{abstract}

Keywords: Paula Frassinetti; Education project; Pedagogical intuitions; Dorothean Schools.

A proposta deste trabalho é estudar a Igreja católica e a educação feminina no século XIX, tendo como recorte a trajetória da constituição do projeto educativo dos Colégios Doroteanos (presentes na Itália, em Portugal e no Brasil); tecido e desenvolvido por Paula Frassinetti ${ }^{2}$ a partir de suas intuições pedagógicas ${ }^{3}$.

\footnotetext{
- Mestre em Educação - Departamento de Ciências Sociais - IMESB - Instituto Municipal de Ensino Superior de Bebedouro - Rua Nelson Domingos Madeira, 300, CEP: 14706-124, Bebedouro, São Paulo, Brasil. E-mail: lucianasene@mdbrasil.com.br

• Professora Doutora - Programa de Pós-Graduação em Educação - CUML - Centro Universitário Moura Lacerda Rua Padre Euclides, 995, CEP: 14085-420, Ribeirão Preto, São Paulo, Brasil. E-mail: aledmcosta@uol.com.br
} 
A abordagem teórica da pesquisa compreende um referencial bibliográfico sobre a educação feminina no século XIX, por meio da releitura de documentos escritos por Paula Frassinetti à luz de reflexões filosóficas e pedagógicas de seu projeto educativo, formulado a partir de 1834, quando iniciou suas atividades educacionais em Quinto, na Itália, até 1882, ano de sua morte. Esse intervalo compreende o período histórico analisado.

A metodologia utilizada consiste nas pesquisas histórica e documental, cujas fontes são as Cartas deixadas por Paula Frassinetti e as Constituições de 1851, as quais adquirem também uma dimensão de fato histórico, uma vez que se tornam, segundo Barros (2005), testemunho ou discurso de uma época. Em razão disso, em todo o trabalho, foi mantida a grafia original das fontes.

O trabalho tem como preocupação analisar e interpretar as fontes históricas com um compromisso social e ético, como revela Garcia (2003, p.11): "se a escola é o fim de nossas pesquisas e de tudo o que escrevemos, o resultado de nossas pesquisas deveria a ela chegar e, de algum modo, a ela beneficiar".

Era no cotidiano escolar, respeitando as necessidades e o contexto histórico e cultural, que Paula Frassinetti transmitia suas intuições pedagógicas através das cartas escritas às Irmãs Superioras dos Colégios Doroteanos. As diretrizes da Congregação transmitidas pelas Constituições e Regras do Instituto iluminavam as práticas educativas, ao constituírem o seu projeto educativo.

A Congregação tinha como missão educativa "evangelizar através da educação com preferência pela juventude e pelos mais pobres" (CONSTITUIÇÕES, art. 26. apud CONGREGAÇÃO DE SANTA DOROTÉIA DO BRASIL, 2003, p.46).

As intuições pedagógicas de Paula Frassinetti são aqui estudadas como categorias de análise, de acordo com as concepções da Igreja no século XIX, voltada às instituições educativas femininas, ou seja, ao catolicismo conservador, conhecido como Ultramontano ${ }^{4}$.

As instituições escolares administradas pelas Dorotéias assumiram a missão de educar as jovens dentro da moral católica, optando pelo regime de internato, por entenderem que esse seria o melhor modelo pedagógico para formar jovens cultas e devotas para uma vida adulta responsável.

As intuições pedagógicas de Paula Frassinetti que contribuíram para a constituição de seu projeto educativo são: diálogo, testemunho, a formação das Irmãs: entre o cultural e o espiritual, coragem e audácia, educar pela via do amor e do coração, suavidade e firmeza, a prudência, obediência, perseverança, fé e incentivo à prática das virtudes: simplicidade, humildade, caridade, alegria, ternura para as Irmãs e alunas,.

O diálogo constituía a via fundamental para a construção do Projeto Educativo de Paula Frassinetti. Em suas Cartas, ela recomendava que houvesse paciência, prudência, equilíbrio; em uma permanente atitude de escuta para que fossem resolvidos os impasses do dia-a-dia. Propunha paciência e oração como resposta para os problemas, sugerindo o diálogo entre as partes e Deus: 
“com a oração tudo se obtém e tudo se vence” (FRASSINETTI, 1987, v.I. Carta 331, Roma, 24 de Maio de 1868, p.572).

Paula Frassinetti soube dialogar nos mais diversos momentos de sua vida: em reunião com a Congregação, no pedido de aprovação da Congregação para a Igreja, nas dificuldades financeiras, nos problemas para atender à demanda de expansão do Instituto, na alegria diante dos resultados obtidos nas diferentes casas do instituto, nas celebrações e festividades, nas preocupações com as doenças das Irmãs e alunas e nas calamidades públicas decorrentes do momento histórico vivido; situações registradas em suas Cartas às outras Irmãs, à sua família, às autoridades religiosas e aos pais das alunas.

Destaca-se um exemplo retirado das Constituições, no capítulo que se intitula "Aviso às Mestras acerca dos seus deveres", em que o diálogo aparece implícito, assim como o bom senso, o equilíbrio, a prudência, a imparcialidade e a justiça:

As que forem encarregadas da educação das meninas se guardem cuidadosamente de toda parcialidade e preferências. Com ânimo sem sempre igual, mostrem uma perfeita justiça para com todas, evitando a severidade excessiva para com umas e indulgência para com outras (CONSTITUIÇÕES, 1999, p.69).

O diálogo para Paula Frassinetti pode ser traduzido como o respeito fundamental ao outro; para que ele aconteça, é necessário ter atitude de escuta e também saber silenciar-se quando o momento exige.

O testemunho e o horizonte para Paula Frassinetti eram o cristianismo, apoiado pela fé, esperança, amor e ação; gostava de recorrer ao exemplo da vida dos santos; ao testemunho deles, que lhe serviam de espelho para as ações do cotidiano. Por intermédio de sua visão de educação, orientou a Superiora da Casa de Gênova como tratar uma Irmã com dificuldades, assim como aproveitar suas aptidões e habilidades para a formação das noviças e aspirantes:

A Irmã Galli é uma alma bendita, com pouquíssima cabeça; por isso, tem necessidade de ser muito ajudada espiritualmente... Portanto, sirva-se dela para ensinar desenho e bordados; nestas duas coisas é hábil. Mas não lhe confie uma classe de alunas, porque as não sabe manter [...] (FRASSINETTI, 1987, v. II. Carta 582, Roma, 5 de Maio de 1873, p.297).

A formação cultural e espiritual das Irmãs era uma das maiores preocupações de Paula Frassinetti, principalmente quanto à preparação para assumirem o papel de Mestras. Priorizava os exemplos de atitudes, como relata numa Carta: “A instrução moral nos noviciados é necessaríssima, mas deve estar unida à prática, porque de contrário saberão falar da virtude, mas não a saberão praticar" (Paula Frassinetti - Carta 191, Roma, 10 de janeiro de 1862). Ainda de acordo com as Constituições, orientava: 
Para assumir uma classe, não é suficiente ser instruídas, mas é necessário ainda conhecer perfeitamente os fundamentos das coisas que se ensinam, a fim de estar prevenidas para explicá-los às alunas, com brevidade, clareza e precisão (CONSTITUIÇÕES 1999, p.71).

O interesse dela pelo desenvolvimento cultural das Irmãs revelava-se quando dizia que umas deviam ensinar as outras, com o objetivo de aproveitá-las futuramente; por exemplo, no ensino da língua francesa:

Procurem animar-se mutuamente, e o que uma sabe ensine-o à outra. Peça à Superiora $^{5}$ que vos fale em francês e, se puder, que vo-lo ensine; e entre vós esforçai-vos por praticá-lo, especialmente no recreio, e assim as tolices que disserdes servirão para vos fazer rir (FRASSINETTI, 1987, v. I. Carta 169, Roma, 16 de julho de 1860 , p.263).

Paula Frassinetti, por meio das Cartas às Superioras das Casas da Congregação, mostrava a relevância da formação das Irmãs, tanto do ponto de vista intelectual, quanto espiritual. Expressava isso das mais diferentes formas: advertindo, elogiando, motivando, encorajando; enfim, sempre congratulando as irmãs que realizavam iniciativas próprias, visando à formação das Mestras.

Por conta de Decretos Oficiais, que passaram a exigir diplomas, preocupou-se mais ainda com a formação das Mestras e como as adaptar às mudanças. Em Carta para a Irmã Josefina Pingiani, relata as sucessivas mudanças de Irmãs que era obrigada a realizar: "Nós também estamos todas bem, mas muito atrapalhadas com os novos métodos. Tive de mudar quase todas as Irmãs, quer para fazer exames, quer para prover de mestras diplomadas as diversas casas" (FRASSINETTI, 1987, v. II. Carta 542, Roma, 7 de Novembro de 1872, p.223).

Com a expansão da Congregação e pedidos de criação de mais Casas, fazia-se necessário o investimento na formação das noviças. Problema que se inicia quando precisou fazer ajustes, como o remanejamento de Irmãs de uma escola para outra; que muitas vezes prejudicava um colégio em detrimento de outro.

A coragem e a audácia eram exigências para alcançar seus sonhos e assumir sua missão. Por meio das cartas, ela revelava sua pedagogia do encorajamento ${ }^{6}$. Paula Frassinetti acreditava:

que a coragem deveria ser uma das formas de estimular o processo de aprendizagem, ou seja, encorajar as educandas passava a ser uma forma de promovê-las, para o desenvolvimento de suas competências. Procedimento comum a essa situação era a emulação, até certo ponto, a competição, que assumia um caráter saudável, na medida em que oportunizava a percepção do valor de cada um, sem que isso fosse motivo de desprezo para os demais (COSTA et al., 2002, p.48).

Ela mostrou coragem e audácia quando aceitou o convite do Bispo de Pernambuco para fundar uma Casa fora da Europa; especificamente, no Brasil, em Recife. 
Em Carta para a Mestra Geral em Recife, pregava a pedagogia do encorajamento, exortando as virtudes da coragem, confiança e generosidade: “Coragem, minha querida Irmã Virgínia: é grande e forte, não queira por caridade abrigar no seu peito um coração pequeno, mas procure dilatá-lo quando puder!” (FRASSINETTI, 1987, v.I. Carta 303, Roma, 27 de Agosto de 1867, p.508).

A via do coração e do amor é uma intuição que se transformou também em um dos princípios de sua prática pedagógica, na medida em que a amorosidade deveria ser um recurso metodológico das Mestras.

Segundo Costa et al. (2002, p.43): “quando Paula nos aponta para a via do coração e do amor, como condição para o trato com as meninas, nos chama para um olhar de sensibilidade e de afeto, bem como, para a responsabilidade de quem assume, com paixão, a tarefa de educar".

Paula Frassinetti, escreve Rossetto (2004, p.90), “fazia tudo com amor e por amor. Até as repreensões eram repletas de afabilidade para convencer e mover, não o sentimento, mas a vontade de melhorar". Como exemplo, a Carta enviada para a Irmã Luísa Gianelli traz: "minha querida Filha, as pessoas não as podemos formar todas a nosso modo. E como poderíamos exercitar a paciência, se todos tivessem o nosso feitio e pensar?” (FRASSINETTI, 1987, v. I. Carta 131, Roma, 19 de Setembro de 1857, p.192).

Em suas atitudes, revelava a ternura e o carinho com que satisfazia as solicitações vindas das Irmãs do Brasil, procurando atender os mínimos pedidos de materiais necessários para a Academia ${ }^{7}$ :

As medalhas também tive de esperar que as cunhassem na Casa da Moeda. Para os lavores não se encontra nada; para conseguir canutilhos que lhe mando, teve de se correr Roma inteira, e tivemos de comprar os que havia; não há de outras cores. Também para os bordados a branco, mandei procurar em todas as lojas e não encontrei melhor do que o pouco que lhe envio.

Os colarinhos já não se usam, e por isso apenas lhe mando setenta, os melhores que se encontraram. Com a guerra, já nada vem; o comércio está paralisado, e não há senão rebotalhos ${ }^{8}$, antigos e caros (FRASSINETTI, 1987, v.I. Carta 421, Roma, 4 de Setembro de 1870, p.761).

Enfim, a via do coração e do amor foi o caminho escolhido por Paula Frassinetti para concretizar a missão idealizada para seu projeto educativo, que se efetiva pelo envolvimento, pela afetividade e pela conquista de toda a comunidade educativa.

Com suavidade e firmeza, Paula Frassinetti administrava a Congregação, e, por meio de seu exemplo e recomendações, ensinava a importância dessa intuição para ser usada por todos, nos diferentes momentos de tomada de decisão. Na realidade, segundo Costa et al. (2002), essa intuição deve ser conduzida com equilíbrio entre afetividade e razão, com cautela e prudência na hora da correção. 
Ao escrever para a Vice-Superiora da Casa de Fabriano desaprova com firmeza a solicitação do bispo para mudança na administração, ocorrida sem o seu conhecimento. Era fundamental para ela seguir as Constituições, os princípios da Congregação e fidelidade à Superiora:

Surpreendeu-me a sua prezadíssima carta de 12 do corrente. Não sabia absolutamente nada sobre a renúncia da Administração e desagrada-me bastante que se tenha feito, contra toda a regra, sem o meu conhecimento. Mais me desagrada que para ter aí outra Irmã, quer dizer, para fazer uma mudança tenham recorrido ao Bispo'. Minha caríssima Filha, este é o primeiro caso que me acontece; e antes Deus destrua o Instituto que permitir que os seus membros caiam na tão funesta desordem de recorrer aos Superiores externos em vez das legítimas Superioras (FRASSINETTI, 1987, v. I. Carta 168, Roma, 16 de Junho de 1860 , p.261).

Em carta à Irmã Josefina Troiani informa sobre as três Irmãs enviadas para Gênova, assim como orienta e recomenda como cada uma deve ser aproveitada no trabalho educativo. Mostrando firmeza nas críticas, mas procurando suavizar, ressaltavam-se as suas qualidades:

Nada lhe digo sobre o carácter da Irmã Galli, porque a Irmã Pingiani ${ }^{10}$ a conhece; recomendo-lhe apenas que procure afeiçoá-la a si. A Irmã Federici tem óptimas qualidades, bom êxito nos estudos, é activa e atrai muito a juventude; mas ainda tem muitos defeitos, pelo que é necessário que a Irmã Catarina ${ }^{11}$ se lhe afeiçoe e a trabalhe. A Irmã Recchioni só serve para lavores nas escolas das pobres e nas classes das pequeninas, ou para a rouparia, etc (FRASSINETTI, 1987, v. II. Carta 543, Roma, 10 de Novembro de 1872, p.225).

Em outra circunstância, firme, no momento de tomada de decisão, expôs ao Padre Arcanjo Centi os motivos pelos quais a sobrinha dele deveria ser despedida do noviciado em Gênova:

A penúltima vez que fui a Gênova, em Julho de 1871, descobri na sua sobrinha certos defeitos que não são compatíveis com uma religiosa, isto é, pouco cuidado na observância da disciplina regular, aliás muita facilidade em transgredir as Santas Regras, com mau exemplo para as outras noviças. Além disso, muita facilidade em referir os defeitos alheios, semeando assim discórdias na comunidade e provocando má disposição das súbditas para com a Superiora, e outras coisas semelhantes (FRASSINETTI, 1987, v. II. Carta 600, Roma, 20 de Outubro de 1873, p.329-330).

Paula Frassinetti dizia: "a firmeza seja sempre temperada com a suavidade nos modos e nas palavras” (FRASSINETTI, 1987, v.II.Carta 801, Roma, 31 de julho de 1877, p.712). Assim, todas as Irmãs deveriam, com equilíbrio, fazer uso da firmeza e suavidade na hora de educar e na hora de punir.

A prudência era muito importante para a organização da instituição. Em Carta para a Irmã Luísa Gianelli, enviada a Gênova para assumir a direção e, assim, reorganizar o Instituto naquela cidade, Paula Frassinetti concede autonomia para que esta pudesse resolver os impasses daquele 
momento: "não me admira que tenha encontrado nessa casa uma babilônia em tudo. Por agora é preciso ter paciência; mas, pouco a pouco, é necessário transformá-la segundo o Instituto; e quem não quiser que se vá em boa hora" (FRASSINETTI, 1987, v. I. Carta 125, Roma, 7 de Maio de 1857, p.176).

Paula Frassinetti tinha bom senso e agia com equilíbrio em suas decisões; mostrava prudência na divulgação de fatos extraordinários. Para ilustrar isso, podemos citar um trecho de uma Carta que ela dirige à Irmã Luísa Gianelli: “Quanto ao que me diz acerca das duas meninas que viram Nossa Senhora mover os olhos, não o refira a ninguém. Esteja bem atenta para dominar a fantasia e fazê-la dominar às outras, a fim de que não seja posto a ridículo o Instituto” (FRASSINETTI, 1987, v. I. Carta 159, Roma, 29 de Agosto de 1859, p.244).

Em Carta à Superiora de Gênova, Paula Frassinetti aconselhou prudência para a admissão das educandas:

\begin{abstract}
Neste momento recordo-me de que a Irmã Elisa Vassallo me disse, há tempos, que a Irmã recebeu aquela sua parente, se não me engano, Penna; por caridade, esteja atenta para não introduzir a malícia no colégio. Se ainda não tiver entrado, informe-se bem antes de a receber; e, se já tiver entrado, procure que a vigiem bem. Para estragar um colégio, basta um nada, e para o recompor, é preciso a mão de Deus (FRASSINETTI, 1987, v. I. Carta 209, Roma, 3 de Maio de 1864, p.343).
\end{abstract}

Paula Frassinetti comenta com a Superiora de Gênova sobre a probabilidade de serem expulsas de Roma, onde a perseguição das ordens religiosas já tinha se iniciado. Muitos religiosos tiveram suas casas tomadas, e tudo levava a crer que a sua Congregação já estaria na lista, e advertiu: "mas ainda não está decidido por quem devemos ser devoradas: se pelo Governo, se pelo Município, se pela Comissão de Caridade.” (FRASSINETTI, 1987, v. II. Carta 619, Roma 1873, p.363).

A prudência para ela significa saber esperar o momento certo, ter paciência e atitude de escuta diante de situações difíceis; ter equilíbrio para não agir precipitadamente; enfim, ser prudente, mas firme na hora da tomada de decisão.

O incentivo à prática das virtudes: simplicidade, humildade, caridade, alegria e ternura nas Irmãs e nas alunas era, para Paula Frassinetti, um dos princípios básicos para a formação dos valores.

Paula Frassinetti, escrevendo para a Superiora do Colégio de Albaro, alegrou-se por saber que possuía muitas alunas, e que elas se empenhavam para viver intensamente as comemorações à Maria, durante o mês de maio: "Alegra-me muitíssimo saber que o Colégio é tão numeroso e que as alunas são tão boas e fazem com empenho o mês de Maria" (FRASSINETTI, 1987, v. II. Carta 646, Roma, 16 de Maio de 1874, p.417). 
Nos colégios da Congregação, segundo Paula Frassinetti, deveriam reinar a simplicidade, a humildade, a caridade, a alegria e a ternura; virtudes importantes ao desenvolvimento de seu projeto educativo, voltado para a educação das jovens.

A Obediência, Perseverança e Fé eram qualidades requeridas na admissão de candidatas ao Instituto, senão elas não perseverariam.

É necessário acautelar-se, porque, se entram sem generosidade e sem as qualidades requeridas, não podem perseverar; e, se ficam, são uma verdadeira cruz e um verdadeiro dano. Falo por experiência: é melhor ter um dedo a menos do que tê-lo sempre a doer (FRASSINETTI, 1987, v. I. Carta 193, Roma, 4 de Agosto de 1862, p.313).

Em Carta a Superiora de Bolonha, solicita um sacrifício desta Casa em nome da expansão da Congregação, enviando duas Irmãs para trabalharem em Tivoli. Lembra também a importância da obediência, quando deixa claro que em qualquer situação contrária a esse pedido, ela se responsabilizaria pelas consequências:

Não deixe de praticar a obediência como a exige o nosso Instituto, quaisquer que sejam as dificuldades que se lhe apresentem contrárias a esta disposição: deixe-me a mim toda a responsabilidade do resultado, Obedeça, e Deus (abençoará) em si toda a comunidade (FRASSINETTI, 1987, v. I. Carta 272, Roma, 02 de Novembro de 1866, p.451).

Preocupada com o contexto histórico do país, respondeu uma Carta da Superiora de Gênova, negando a peregrinação das alunas ao Santuário de Savona, chamando atenção para a importância da obediência:

Quanto a levar as alunas ao Santuário de Savona, não é do meu gosto; não são tempos próprios para passear, principalmente com alunas. E às Irmãs desejo que se desloquem unicamente quando a obediência as manda de um lugar para outro (FRASSINETTI, 1987, v. II. Carta 461, Bolonha, Setembro de 1871, p.48).

Em correspondência à Superiora de Recife, lamentou a situação por que passava Roma, pela acentuada perseguição às escolas católicas, que lutavam para poderem continuar a tarefa da educação; temia pelo destino da juventude:

Não se podem enumerar os sacrifícios que fazem os Institutos Religiosos para conservar alguma parte da instrução, mas receio que se não consiga, porque querem a juventude toda nas suas mãos. Oh, pobre juventude!!! (FRASSINETTI, 1987, v. II. Carta 532, Roma, 16 de Setembro de 1872, p.199).

Após realizar um diagnóstico da situação do Instituto, Paula Frassinetti escreveu a todas as Superioras das Casas, na Europa, para convocá-las para a Primeira Congregação Geral, cuja 
finalidade "será dar ao nosso Instituto a estabilidade e o vigor que provêm da uniformidade de espírito e de observância regular, em plena conformidade com as mesmas Regras e Constituições” (FRASSINETTI, 1987, v. II. Carta 773, Roma, 6 de Maio de 1876, p.662-663).

Em outra Carta endereçada a todas as Superioras, após analisar a situação de todos os Colégios do Instituto, orientou e recomendou sobre o exercício e as competências do ofício de Mestra Geral, dentro da ordem e obediência às Constituições:

É, portanto, dever da Mestra Geral velar para que tudo se faça com ordem e segundo as nossas Regras; mas, quanto ao resto, não pode fazer inovações de espécie alguma sem o consentimento explícito da Superiora da casa, à qual deve dar minuciosas contas de tudo [...] (FRASSINETTI, 1987, v.II. Carta 856, Roma, 8 de Abril de 1880, p. 772-773).

A obediência, a perseverança e a fé eram intuições sempre presentes nas mensagens de Paula Frassinetti a todas as Irmãs. Muitas vezes, por meio de seu próprio exemplo, mostrou a prática dessas virtudes, que, na realidade, seriam o reconhecimento dos limites e da fragilidade das pessoas. A obediência, para ela, pode ser expressa pela seguinte frase: “Tudo o que Deus quer também o quero eu” (FRASSINETTI, 1987, v.I. Carta 220, Roma, 17 de Setembro de 1864, p.362).

O Projeto Educativo de Paula Frassinetti, que há mais de dois séculos são aplicados nas Escolas Dorotéias, foi construído a partir de suas intuições pedagógicas, segundo o contexto histórico e cultural da época, observando as peculiaridades de cada Casa da Congregação. Hoje está presente em quatro continentes: Europa (Itália, Espanha, Portugal, Inglaterra, Albânia, Suíça e Ilha de Malta), África (Angola, Camarões, São Tomé e Príncipe e Moçambique), Ásia (Filipinas e Taiwan) e América (Estados Unidos, Brasil, Argentina e Peru). Concebe o ensino como privilégio da escuta do outro pela "via do coração e do amor".

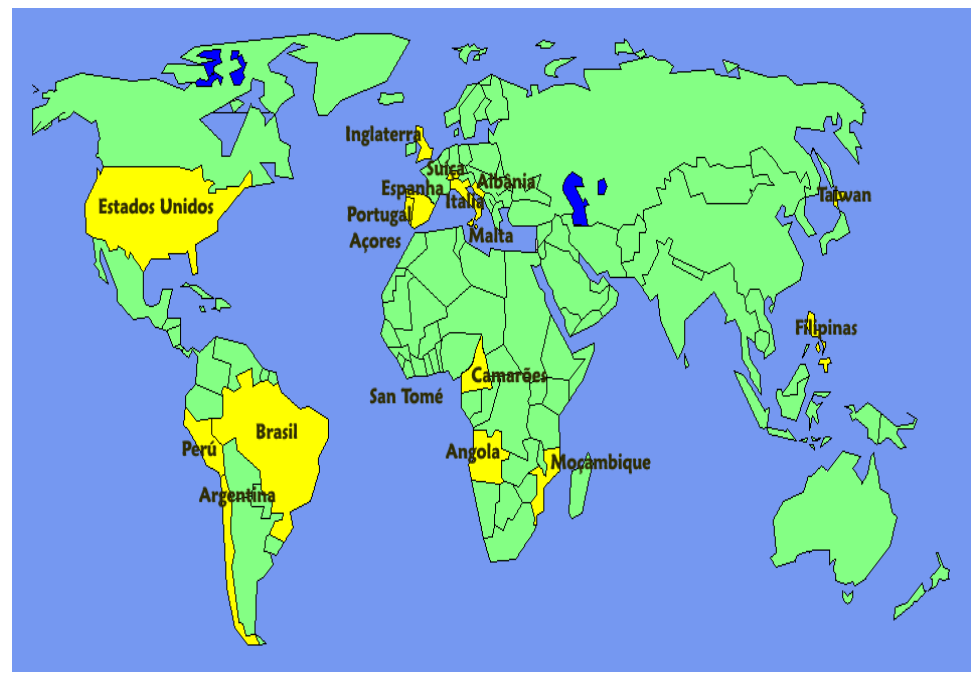

FIGURA 01: Mapa da Congregação de Santa Dorotéia no mundo Fonte: Congregação de Santa Dorotéia - Roma 
A busca pela educação nos Colégios Doroteanos no Brasil atendia a uma exigência da oligarquia brasileira, que percebia a necessidade de dar instrução para suas filhas. Assim, os colégios ofereciam duas formas de ensino: o externato e o internato. $\mathrm{O}$ internato veio ao encontro do desejo da oligarquia, pois corresponde a um sistema educacional conservador, que ensinasse a suas filhas o cultivo da religiosidade e da moralidade; refere-se também a uma instrução cultural e artística dentro da ótica humanista.

$\mathrm{Na}$ organização pedagógica e no funcionamento do internato das escolas femininas católicas, ressaltamos a relevância da tônica ornamental na formação cultural das jovens educandas, que exemplificaremos por meio das seguintes passagens citadas por Manoel:

Desde o ingresso da criança nesses colégios, essa preocupação se tornava manifesta, com base no próprio programa da classe preparatória, que estipulava a ordem, o bom comportamento e a polidez como as três práticas iniciais e obrigatórias dos objetivos instrucionais.

Daí e diante, o treinamento diário das educandas se dava ao redor dessas práticas de sociabilidade, tendo como referência a etiqueta francesa.

Ao lado desse exercício cotidiano das práticas de polimento social, uma série de matérias era ensinada de modo a construir o seu lastro cultural completando, assim, o projeto educacional (MANOEL, 1996, p.84).

Ainda segundo Manoel:

Se não perdermos de vista que 'prendas domésticas' para o internato não significava aprender a lavar, passar, varrer e cozinhar, mas significava 'obras e gosto', temos claro que a expectativa da oligarquia em obter filhas polidas, sociáveis e "ornadas" estava sendo atendida plenamente (MANOEL, 1996, p.85).

A organização do internato aparece com destaque no Capítulo V das Constituições:

As alunas do internato serão divididas em diversas classes, segundo sua idade e capacidade. Haverá uma Mestra particular na direção de cada classe e mais uma Mestra geral do internato, cujo ofício será dirigir e ajudar as Mestras particulares e velar sobre todas as divisões do ensino, e fazer observar exatamente tudo o que é estabelecido no plano dos estudos (CONSTITUIÇÕES, 1999, p.67-68).

De acordo com Manoel:

Cada passo era medido, estipulado por um conjunto de regras destinadas a modelar a mulher que, além dos ornamentos culturais, da polidez, portasse a marca indelével da educação conservadora. Por isso gestos, comportamentos, linguagem, tudo era vigiado, controlado, moldado (MANOEL, 1996, p.78). 
Uma das principais regras das Escolas Dorotéias era manter as jovens sob controle e vigilância, durante todo o dia, visando à preservação de sua virgindade e à conservação de sua inocência; também à prevenção dos perigos (AZZI, 2000).

Em um dos itens das Normas das Escolas Dorotéias, constava o seguinte detalhe:

Serão vigiadas atentamente as educandas para impedir que jamais lhes sejam dados livros, cartas ou quaisquer escritos sem a permissão da Mestra Geral, e sem que ela os tenha primeiro visto e conhecido. Todas as que são empregadas na vigilância das meninas, considerem esse ofício como o mais sagrado dos deveres (AZZI, 2000, vol.2, p.27).

Em carta dirigida às Superioras e Consultoras das Casas do Instituto, Paula Frassinetti alertou para os cuidados que deviam ter com a vigilância nos colégios:

Se os Colégios forem organizados segundo as Regras, daí resultará grande benefício para o Instituto, porque adquirirá boas vocações, e grande benefício também para a sociedade porque, saindo as jovens bem fundadas numa piedade sólida, serão anjos de paz nas suas famílias, o que redundará em grande glória para Deus, fim único dos nossos trabalhos (FRASSINETTI, 1987, v. I. Carta 229, Roma, 20 de Abril de 1865, p.380).

A religião deveria ser a base e o fim da educação; portanto, o restante seria apenas acessório, como ordenavam as Constituições (1999, ART. 26): "Educar, para nós, significa deixar-nos possuir pela pedagogia do Evangelho".

As alunas deveriam estudar também as ciências humanas, a fim de oferecer-lhes suporte para servir a Deus no mundo. Como exemplifica as Constituições, o estudo deveria:

Limitar-se a ensinar as educandas o que convém a uma pessoa chamada a viver cristãmente no mundo, segundo as circunstâncias do seu estado e condição. Por isto, além do estudo da leitura e da escrita, que convém a todos, se lhes dará alguns conhecimentos elementares de gramática, história, geografia e aritmética. Não se descuidava de cultivar-lhes a memória, fazendo-as aprender cuidadosamente o que mais importa saber para o modo de proceder na vida e para ornamento da boa sociedade (CONSTITUIÇÕES, 1999, p.66).

As alunas também deveriam conhecer bem o catecismo, ser orientadas para a Primeira Comunhão, para os santos sacramentos e para o respeito e amor à Igreja. Havia um regulamento que tratava das ocupações diárias e dos exercícios de piedade, do qual faziam parte:

As orações da manhã e da noite, a Santa Missa, a oferta das ações, um quarto de hora de meditação, exame de consciência, leitura espiritual, visita ao Santíssimo, se o tiverem em casa: a confissão ao menos cada quinze dias, e a comunhão, quando forem julgadas dignas dela (CONSTITUIÇÕES, 1999, p.63-64). 
Mostrava-se a importância pelo desprezo e, por conseguinte, pelo afastamento das ostentações do mundo e da escravidão da moda, assim como instruía à devoção ao Sagrado Coração de Jesus e à Santíssima Virgem:

o desprezo e afastamento das vãs ostentações do mundo, da escravidão da moda, tão contrário à humildade e à decência que o cristianismo prescreve. Que se façam conhecer e vivamente considerar os perigos dos bailes e teatros, esforçando-se por colocá-las em condições de resistir as seduções do mundo que procurará atraí-las (CONSTITUIÇÕES 1999, p.65).

O silêncio era outro instrumento pedagógico muito importante:

Discrição que se faz com que uma mestra se cale quando não é preciso falar, e fale quando é necessário. O silêncio produz a ordem e a tranqüilidade da classe, assegura o progresso das alunas, evita muita fadiga inútil e nociva à saúde das Mestras. A experiência prova que as mestras que falam muito são pouco ouvidas e pouco consideradas. É preciso abster-se de falar muito alto na classe, pois atordoa e cansa as meninas, sem nenhum proveito próprio para elas nem para as mestras, que perdem a saúde que deveriam conservar para poderem trabalhar para a maior glória de Deus (CONSTITUIÇÕES, 1999, p.72).

As Constituições indicavam que, sempre que possível, a escola para as meninas externas deveria funcionar em local separado das internas; mais especialmente as da classe mais carentes, que deveriam ficar na escola o maior tempo possível para aprender o catecismo e a instrução conveniente à sua idade, capacidade e condição.

As escolas tinham uma Mestra-Geral e tantas outras Mestras quantas fossem necessárias para a instrução das alunas, a fim da manutenção da ordem. A Mestra-Geral das escolas estava sob as ordens da direção da Superiora da Casa.

A idade para admissão de alunas era a partir dos seis anos, sendo divididas em três classes: a primeira composta pelas mais capazes e instruídas (para entrar nessa classe era necessário saber o catecismo, ler correntemente e já ter iniciado o processo de aquisição da escrita); a segunda era composta pelas meninas menos instruídas, mas que já começaram a ler, para que pudessem estudar o catecismo; a terceira classe era composta pelas meninas menores que precisavam aprender a leitura. Havia distribuição de três prêmios (primeiro, segundo e terceiro lugares) para cada classe, após realização de exame de toda a matéria ensinada durante o ano; eram avaliados o progresso e a boa conduta das alunas. Era dado também um prêmio distinto de sabedoria para a aluna mais aplicada.

O projeto educativo de Paula Frassinetti priorizava um currículo que ensinasse noções básicas de formação humanística e moral, com uma tônica nas artes em geral e no ensino dos bons modos, assim como havia uma preparação das alunas para as apresentações do final do ano; no caso, o 
ensino do canto, piano e declamação, como relata Manoel ao analisar os colégios católicos femininos:

Esses colégios não preparavam eremitas para a vida contemplativa, mas jovens que ocupariam lugares centrais na sociedade. Por isso, a recusa do corpo estancava nos limites da polidez: era necessário adestrá-lo para executar os movimentos e os gestos conforme um conjunto de etiquetas que abrangiam desde o sentar-se corretamente e comer maçãs com faca e garfo, até a maneira correta de abrir o lenço e assoar-se (MANOEL, 1996, p.80).

Dessa maneira, ao colocar suas filhas nas escolas da Congregação das Dorotéias, os pais esperavam que as jovens rompessem com seus:

hábitos de rusticidade, e fossem preparadas para os modos de vida nas cidades. Ao mesmo tempo, porém, desejavam que essa nova educação mantivesse também padrões morais conservadores, sem qualquer influência do espírito libertário que começava a se afirmar em alguns setores bem específicos e mais intelectualizados da população... Em termos de educação moral, de fato, as alunas das dorotéias eram orientadas para a vida familiar, sendo o lar considerado o lugar por excelência do sexo feminino. Nas aulas, eram também inculcados o respeito à autoridade, a submissão e a obediência, bem como formas de conduta recatada, condição indispensável para a guarda da virgindade (AZZI, 2000, p.223).

Para que o processo educativo funcionasse a contento, Paula Frassinetti recomendava às Mestras a importância da vigilância, disciplina, limpeza, zelo e ordem, em todos os espaços escolares. Respeitando a individualidade e as dificuldades das alunas, procuravam dar atenção especial às externas, por estarem expostas aos perigos da sociedade.

As Irmãs Dorotéias priorizavam as devoções à Maria Imaculada, ao Coração de Jesus, a São José e às associações religiosas: Filhas de Maria e dos Santos Anjos, as quais eram estratégias de fortalecimento da fé católica, da manutenção da virgindade até o casamento e da fidelidade às normas de conduta moral:

As Dorotéias, preocupadas com a formação religiosa das jovens, davam ênfase aos sacramentos da confissão e da comunhão. Irmã Pingiani narra que:

Diversas alunas, além de se confessarem e comungarem no colégio faziam questão de promover essa prática sacramental em seu lar durante o período de férias. Algumas tinham feito confessar a mãe, outras tinham obtido do pai que fizesse confessar os escravos, e lhes fizesse pregar uma missão. Outras tinham instruído suas escravazinhas, e as tinham preparado para a primeira comunhão (PINGIANI, 1870, p.1 apud AZZI, 2000, p.177).

O Projeto Educativo de Paula Frassinetti propunha uma formação integral das alunas, dentro de uma linha evangelizadora, imbuída de uma pedagogia do encorajamento, pela via do coração e 
do amor. Como ela mesma dizia: "onde não posso chegar com a pena, procuro chegar com o coração" (FRASSINETTI, 1987, v. I. Carta 293, Roma, 6 de Junho de 1867, p.493).

As fontes pesquisadas indicam que, por meio de suas intuições pedagógicas, Paula Frassinetti construiu e desenvolveu o seu projeto educativo de acordo com as necessidades e o contexto histórico e cultural do século XIX, respeitando as diversidades locais e o perfil das alunas. As instituições escolares administradas pela Congregação de Santa Dorotéia assumiram a missão de educar as jovens dentro da moral católica, tanto na Europa (Itália e Portugal) como no Brasil. Assim, o projeto educativo das Escolas Dorotéias vai ao encontro da representação social da mulher no século XIX, e a reforça, dentro de uma estrutura conservadora, de acordo com a ótica da Igreja católica: a mulher piedosa, dentro do espaço doméstico, e com o reconhecimento social, enquanto mãe, esposa e dona-de-casa.

Os princípios, valores e fundamentos implícitos nas intuições pedagógicas de Paula Frassinetti alicerçaram e nortearam o seu projeto educativo (diálogo, educação pela via do coração e do amor, suavidade e firmeza, respeito à individualidade, evangelização da comunidade educativa, exercícios espirituais, sacramentos, retiros e formação de liderança).

Os colégios doroteanos, estabelecidos durante todo o período estudado (1834 a 1882), localizavam-se na Itália (Quinto, Macerata, Recanati, Nepi, Fabriano, Bolonha, Gênova e Roma), Portugal (Lisboa, Covilhã, Porto, Vila Nova de Gaia e Vila do Conde) e no Brasil (Recife e Belém).

Finalmente, pelo estudo das cartas escritas por Paula Frassinetti, que constituíram a principal fonte e o próprio fato histórico deste trabalho, compreendemos o importante papel das escolas femininas católicas no século XIX; examinamos as intuições pedagógicas de Paula Frassinetti, que deram origem ao projeto educativo e ao currículo das Escolas Dorotéias.

\section{Referências Bibliográficas}

ALMEIDA, Custódio Luís Silva de. Intuição pedagógica de Paula Frassinetti: um olhar filosófico. Recife, PE: Congregação de Santa Dorotéia do Brasil, 2000. 43p.

AZZI, Riolando. Educando pela via do coração e do amor. Rio de Janeiro, RJ: Congregação das Irmãs de Santa Dorotéia no Brasil, 2000, 396p. v. 1.

BARROS, José D`Assunção. O projeto de pesquisa em história. Petrópolis, RJ: Vozes, 2005. 236p.

COSTA, Flávia Fernanda et al. Um olhar sobre a educação... de Paula Frassinetti a Paulo Freire. Porto Alegre, RS: Salles, 2002. 100p.

CONGREGAÇÃO DAS IRMÃS DE SANTA DOROTÉIA. Constituições e Regras do Instituto Religioso das Irmãs Mestras de Santa Dorotéia. Trad. da Província Brasil-Nordeste (Recife, 1969). Porto Alegre, RS, 1999.139p.

CONGREGAÇÃO DE SANTA DOROTÉIA DO BRASIL. Plano trienal de educação 2004-2006: 
Província Brasil Sul pastoral escolar. Belo Horizonte, MG, 2003. 67p.

FERREIRA, Aurélio Buarque de Holanda. Novo dicionário básico da língua portuguesa. Rio de Janeiro, RJ: Nova Fronteira, 1995. 687p.

FRASSINETTI, Paula. Cartas. Congregação das Irmãs de Santa Dorotéia. Edição da Província Portuguesa Sul, 1987. 808p. v. I.

. Cartas. Congregação das Irmãs de Santa Dorotéia. Edição da Província Portuguesa Sul, 1987. 851p. v. II.

GARCIA, Regina Leite. Reflexões sobre a responsabilidade social do pesquisador. In: MOREIRA, Antônio Flávio (Org.) et al. Para quem pesquisamos. Para quem escrevemos: o impasse dos intelectuais. 2. ed. São Paulo, SP: Cortez, 2003, p.11-36.

MANOEL, Ivan A. Igreja e educação feminina (1859-1919): uma face do conservadorismo. São Paulo, SP: UNESP, 1996. 102p.

ROSSETTO, Rosa. Santa Paula Frassinetti. São Paulo, SP: Paulinas, 2004. 221p.

\section{NOTAS}

${ }^{1}$ Parte deste trabalho foi apresentado no VII Congresso Luso-Brasileiro de História da Educação, organizado pela Faculdade de Psicologia e de Ciências da Educação e pela Faculdade de Letras da Universidade do Porto, realizado de 20 a 23 de junho de 2008, na cidade do Porto (Portugal). Para esta versão, foi revisto e ampliado.

${ }^{2}$ Santa Paula, canonizada em 11 de março de 1984, e fundadora da Congregação de Santa Dorotéia.

${ }^{3}$ Paula Frassinetti não tinha formação acadêmica; assim, designou-se chamar de intuições pedagógicas em vez de pedagogia os princípios e valores morais e religiosos que orientaram o seu projeto educativo.

${ }^{4}$ Doutrina política dos católicos franceses (e de outros) que buscavam inspiração e apoio além dos montes; os Alpes e na Cúria Romana. Sistema dos que defendem a autoridade absoluta do Papa em matéria de fé e disciplina (FERREIRA, 1995, p.657).

${ }^{5}$ Irmã Teresa Casavecchia.

${ }^{6}$ Entenda-se como uma resposta de Paula Frassinetti aos conflitos e medos da época, recomendando às Irmãs que não perdessem a coragem diante dos desafios (COSTA et al, 2002).

${ }^{7}$ Espécie de sessão solene ou solenidade no final do ano letivo, em que as alunas apresentariam os seus trabalhos como música, canto, poesia, etc.

${ }^{8}$ Coisa sem valor; ninharia e restos inúteis; refugo; pedacinho.

${ }^{9}$ Monsenhor Antônio Maria Valenziani.

${ }^{10}$ Irmã Teresa Pingiani, Mestra Geral.

${ }^{11}$ Irmã Catarina Podestà. 